\title{
Part-Time Unemployment and Optimal Unemployment Insurance
}

\author{
Susanne Ek* and Bertil Holmlund ${ }^{\dagger}$
}

This version: April 20, 2010

\begin{abstract}
A significant fraction of the labor force consists of employed workers who are part-time unemployed (underemployed) in the sense that they are unable to work as much as they prefer. This paper develops a search and matching model to study the design of optimal unemployment insurance in an economy with unemployment as well as part-time unemployment. Part-time unemployment provides income insurance and serves as a stepping stone to full-time jobs. Unemployment benefits for part-timers make part-time work more attractive relative to both unemployment and employment, thus increasing the outlow from unemployment to part-time work but also reducing the transitions from part-time work to employment. We examine the optimal structure of benefits for unemployed and underemployed workers. We consider optimal replacement rates as well as optimal time limits. The results indicate substantial welfare gains associated with time limits for unemployment benefits as well as for part-time benefits.
\end{abstract}

*Department of Economics, Uppsala University, Box 513, SE-751 20 Uppsala, Sweden Susanne.Ek@nek.uu.se

${ }^{\dagger}$ Department of Economics, Uppsala University, Box 513, SE-751 20 Uppsala, Sweden. Bertil.Holmlund@nek.uu.se 


\section{Introduction}

Conventional measures of unemployment do not capture all dimensions of joblessness. A case in point is underemployment among employed workers, also referred to as part-time unemployment. Workers in this category are employed during a survey week but are unable to work as many hours as they wish. Part-time unemployment accounts for a non-negligible fraction of the labor force. Data from the labor force surveys reveal that part-time unemployment in the United States accounted for 6 percent of the labor force by the end of 2009; unemployment stood at 10 percent during the same period. In Sweden, the corresponding numbers were 5 percent and 8 percent, respectively. On average, part-time unemployed in Sweden work 20 hours per week but report that they would prefer to work around 40 hours.

Research on part-time unemployment has been meager compared to the huge literature on "full-time" unemployment, perhaps reflecting the presumption that underemployment represents less of a social problem than complete joblessness. It is clear, however, that part-time unemployment is of a non-trivial magnitude and raises a number of important policy issues. One issue, hotly debated in some countries, concerns labor market regulation and the case for giving part-timers precedence to full-time jobs. Other issues deal with unemployment insurance and concern the design of benefit levels and potential benefit durations for the unemployed and the underemployed. Our paper contributes to the literature on optimal unemployment insurance with special focus on part-time unemployment. To the best of our knowledge, our paper is the first study that examines optimal unemployment insurance for an economy with both unemployment and underemployment.

We study an economy with two sectors where full-time jobs are offered in one sector and part-time jobs in the other sector. One can think of these sectors as representing two industries; indeed, the data show that the prevalence of part-time unemployment is heavily correlated with industry affiliation, being particularly common in service industries. Unemployed workers prefer full-time jobs but are willing to consider part-time jobs as a stepping stone to full-time jobs. The unemployed worker thus searches for part-time 
as well as full-time jobs and accept the first offer that comes along. The parttimer searches only for full-time jobs and quits her part-time job as soon as a full-time offer comes along.

Unemployment benefits affect search effort among the unemployed as well as among the part-timers. More generous benefits for part-timers reduce the flow from part-time work to employment as part-time status becomes more attractive relative to employment. In that respect, offering benefits to parttimers is akin to in-work benefits, a policy which has received considerable attention in both policy discussions and research. But benefits for part-timers also make part-time status more attractive relative to unemployment, thus increasing the outflow from unemployment to part-time work.

We study the optimal structure of unemployment benefits focusing on benefit levels (replacement rates) and the potential duration of benefit receipt for the unemployed as well as for part-timers. The model is calibrated to Swedish data. We find substantial welfare gains associated with time limits for unemployment benefits as well as for part-time benefits.

\section{The Model}

\subsection{The Labor Market}

We consider an economy populated by individuals with identical preferences. All individuals are labor force participants and workers have infinite time horizons. Workers can be in one of three mutually exclusive states, i.e., they can be fully employed, fully unemployed (referred to as unemployed) or part-time (un)employed (interchangeably referred to as part-timers and underemployed). The size of the labor force is normalized to unity and the labor force identity is written as

$$
e+p+u=1
$$

where $e, p$ and $u$ stands for employment, underemployment and unemployment, respectively. We let index $j, j=e, u, p$, represent labor force states. 
Employed workers can work as much as they prefer whereas part-timers are unable to do so and they can therefore be viewed as involuntary parttime unemployed. Part-timers search for full-time jobs in order to realize their preferred working time. The unemployed search for part-time as well as full-time jobs, recognizing that part-time jobs can provide partial income insurance as well as providing stepping stones to full-time jobs. Search among the unemployed takes place in an undirected fashion: they search for work and whether they become full-time or part-time employed is determined by a random matching process. The probability that an individual unemployed worker ends up as employed depends on the number of vacant full-time jobs relative to the competition she faces from other unemployed as well as parttimers (since both groups compete for full-time jobs). Analogously, the probability that she ends up as part-time employed depends on the number of vacant part-time jobs relative to the number of unemployed (as only the unemployed compete for part-time jobs).

There are two types of firms (two sectors) that offer either full-time or part-time jobs. Let index $k, k=E, P$, represent the type of job where $E$ and $P$ stand for full-time and part-time jobs, respectively. The job finding rates are determined via sector-specific and constant returns matching functions, $M_{k}=m\left(v_{k}, S_{k}\right)$, where $v_{k}$ is the number of vacancies in sector $k$ and $S_{k}$ is the effective number of workers competing for jobs in sector $k$. Labor market tightness for each sector is given by $\theta_{k} \equiv v_{k} / S_{k}$. The rate at which an unemployed worker with search effort $s_{u}$ finds a full-time job is given by $s_{u} m\left(v_{E}, S_{E}\right) / S_{E}=s_{u} \alpha\left(\theta_{E}\right)$, where $S_{E} \equiv s_{u} u+s_{p} p$ is the effective number searchers competing for full-time jobs. The rate at which she finds a part-time job is given by $s_{u} m\left(v_{P}, S_{P}\right) / S_{P}=s_{u} \alpha\left(\theta_{P}\right)$, where $S_{P}=s_{u} u$. Analogously, a part-timer with search effort $s_{p}$ finds a full-time job at the rate $s_{p} m\left(v_{E}, S_{E}\right) / S_{E}=s_{p} \alpha\left(\theta_{E}\right)$. Firms encounter searchers at the rate $q_{k}=m\left(v_{k}, S_{k}\right) / v_{k}=q\left(\theta_{k}\right)$ and thus we have $\alpha\left(\theta_{k}\right)=\theta_{k} q\left(\theta_{k}\right)$. For ease of notation we will sometimes use shorthand notations of the form $\alpha_{E}=\alpha\left(\theta_{E}\right)$ and $\alpha_{P}=\alpha\left(\theta_{P}\right)$.

Full-time as well as part-time jobs are destroyed at the exogenous rate $\phi$. Job destructions always involve job losses for the workers, i.e., entry into 
unemployment. The steady state flow equilibrium conditions for $u$ and $p$ are given as

$$
\begin{aligned}
s_{u}\left[\alpha\left(\theta_{P}\right)+\alpha\left(\theta_{E}\right)\right] u & =\phi(1-u) \\
{\left[s_{p} \alpha\left(\theta_{E}\right)+\phi\right] p } & =s_{u} \alpha\left(\theta_{P}\right) u
\end{aligned}
$$

where the left-hand sides capture the outflows from $u$ and $p$ and the righthand sides the inflows. Employment is obtained residually from the labor force identity as $e=1-u-p$.

\subsection{Workers}

Workers have identical preferences represented by a logarithmic utility function of the form:

$$
v_{j}=\ln c_{j}+\delta \ln l_{j}
$$

where $c_{j}$ denotes consumption and $l_{j}$ stands for leisure. We ignore borrowing and savings so consumption equals income in each state. Let $B$ denote unemployment benefits for the unemployed worker and $b$ benefits for the part-timer. Let $w_{j}$ denote the wage rate per unit of labor input and let $h_{j}$ be working time. The employed worker thus earn (consume) $c_{e}=W_{e} \equiv w_{e} h_{e}$, whereas the part-timer earns $W_{p} \equiv w_{p} h_{p}$. The part-timer's total consumption is thus given by $c_{p}=W_{p}+b$, whereas the unemployed worker's consumption is $c_{u}=B$.

The individual's time endowment is denoted $T$. The time budget restriction for the employed worker is given by $T=h_{e}+l_{e}$; for the part-timer the relevant restriction is $T=h_{p}+l_{p}+s_{p}$; and the unemployed worker faces the restriction $T=l_{u}+s_{u}$. For log utility we thus have

$$
\begin{aligned}
v_{e} & =\ln \left(w_{e} h_{e}\right)+\delta \ln \left(T-h_{e}\right) \\
v_{p} & =\ln \left(w_{p} h_{p}+b\right)+\delta \ln \left(T-h_{p}-s_{p}\right) \\
v_{u} & =\ln B+\delta \ln \left(T-s_{u}\right)
\end{aligned}
$$

We assume that full-timers are free to choose their desired working time. With log utility, this implies $h_{e}=T /(1+\delta)$. Part-timers are unable to realize 
their desired working time so $h_{p}<h_{e}$. Working time for part-timers is taken as exogenous.

Consider the intertemporal objective functions in the three states. Let $U$ denote the expected discounted present value of utility for an unemployed worker, let $P$ be the corresponding value if the person is a part-timer, and let $E$ be the value if the person is employed. The value functions are written as

$$
\begin{aligned}
r E & =v_{e}+\phi(U-E) \\
r P & =v_{p}+\phi(U-P)+s_{p} \alpha\left(\theta_{E}\right)(E-P) \\
r U & =v_{u}+s_{u}\left[\alpha\left(\theta_{P}\right)(P-U)+\alpha\left(\theta_{E}\right)(E-U)\right]
\end{aligned}
$$

where $r$ is the subjective rate of time preference. As usual, the flow value of employment, as given by (8), involves the instantaneous utility $v_{e}$ and a risk of job loss and an associated present value utility loss as the worker switches from employment to unemployment. The flow value of underemployment, as given by (9), involves the instantaneous utility $v_{p}$, the risk of job destruction (the second term on the right-hand side), and also the prospect of making a utility increasing transition to employment (the third term). Finally, the flow value of unemployment, as given by (10), entails the instantaneous utility, $v_{u}$, as well as the possibility of moving to either employment or part-time status. ${ }^{1}$ It is assumed that the parameters of the model are such that the inequalities $E>U, P>U$ and $E>P$ hold.

The value functions can be solved for present value differences. When evaluated at $r \rightarrow 0$, these expressions take the form:

\footnotetext{
${ }^{1}$ The value functions above imply that a job loss for a part-timer results in the same income as is available for a full-time employed worker if laid off. This is realistic (for Sweden) to the extent that the part-timer has a history of full-time work.
} 


$$
\begin{aligned}
E-U & =\frac{1}{A}\left[\left(\phi+s_{p} \alpha_{E}\right)\left(v_{e}-v_{u}\right)+s_{u} \alpha_{P}\left(v_{e}-v_{p}\right)\right] \\
P-U & =\frac{1}{A}\left[\left(\phi+s_{u} \alpha_{E}\right) v_{p}-\left(\phi+s_{p} \alpha_{E}\right) v_{u}-\left(s_{u}-s_{p}\right) \alpha_{E} v_{e}\right] \\
E-P & =\frac{v_{e}-v_{p}}{\phi+s_{p} \alpha_{E}}
\end{aligned}
$$

where $A=\left(\phi+s_{u} \alpha_{E}+s_{u} \alpha_{P}\right)\left(\phi+s_{p} \alpha_{E}\right)$. We have so far ignored taxes but it is clear that a proportional tax on all labor income, including benefits, will have no effect on the present value differences given by (11), (12) and (13).

The part-timer chooses search effort, $s_{p}$, in order to maximize $r P$; likewise, the unemployed chooses her search effort, $s_{u}$, in order to maximize $r U$. The first-order conditions are given as:

$$
\begin{array}{ll}
s_{p}: & \frac{\delta}{T-h_{p}-s_{p}}=\alpha\left(\theta_{E}\right)(E-P) \\
s_{u}: & \frac{\delta}{T-s_{u}}=\alpha\left(\theta_{P}\right)(P-U)+\alpha\left(\theta_{E}\right)(E-U)
\end{array}
$$

These conditions state that the marginal cost of increasing search effort should be equated to the expected marginal gain of doing so. It is clear from the expressions that the marginal gain of increasing search effort is higher for an unemployed worker than for a part-timer. The unemployed worker's returns from additional search involves a chance to land a part-time job as well as a full-time job whereas the part-timer's search is confined to full-time jobs. It follows immediately that an unemployed person allocates more effort to job search than a part-timer, i.e., $s_{u}>s_{p}$. Indeed, it follows that $s_{u}>h_{p}+s_{p}$, implying $l_{u}<l_{p}$ : the unemployed enjoys less leisure than the part-timer.

\subsection{Firms}

Firms operate under constant returns to labor, an assumption that allow us to treat a job as a stand in for the firm (Pissarides, 2000). There are two 
sectors in the economy: full-time jobs and part-time jobs. Jobs of either type are destroyed at the rate $\phi$. A full-time job is never transformed into a parttime job so a worker who loses a full-time job becomes unemployed. Workers and jobs are randomly matched: a firm with a vacant full-time job hires a job searcher at the rate $q\left(\theta_{E}\right)$ whereas a firm with a vacant part-time job finds a worker at the rate $q\left(\theta_{P}\right)$. Let $V_{k}$ denote the present value of opening a vacancy and $\kappa$ the flow cost of a vacancy. The value functions for vacancies then take the form:

$$
\begin{aligned}
& r V_{E}=-\kappa+q\left(\theta_{E}\right)\left(J_{E}-V_{E}\right) \\
& r V_{P}=-\kappa+q\left(\theta_{P}\right)\left(J_{P}-V_{P}\right)
\end{aligned}
$$

Labor productivity, $y_{k}$, and wage rates, $w_{k}$, are exogenous. Productivity and wages are uniform across workers and firms within each sector but may conceivably differ between sectors. The flow values of occupied full-time and part-time jobs are then written as:

$$
\begin{aligned}
& r J_{E}=\left(y_{e}-w_{e}\right) h_{e}+\phi\left(V_{E}-J_{E}\right) \\
& r J_{P}=\left(y_{p}-w_{p}\right) h_{p}+\phi\left(V_{P}-J_{P}\right)+s_{p} \alpha\left(\theta_{E}\right)\left(V_{P}-J_{P}\right)
\end{aligned}
$$

The second value function is slightly non-standard since it incorporates onthe-job search, $s_{p} \alpha\left(\theta_{E}\right)$ : part-timers search for full-time jobs which they land at the rate $s_{p} \alpha\left(\theta_{E}\right)$. When the part-time worker quits, the part-time job becomes vacant. Free entry of vacancies implies $V_{k}=0$ and the resulting two key job creation equations can thus be written as:

$$
\begin{aligned}
& J_{E} \quad: \quad \frac{\left(y_{e}-w_{e}\right) h_{e}}{\phi}=\frac{\kappa}{q\left(\theta_{E}\right)} \\
& J_{P} \quad: \quad \frac{\left(y_{p}-w_{p}\right) h_{p}}{\phi+s_{p} \alpha\left(\theta_{E}\right)}=\frac{\kappa}{q\left(\theta_{P}\right)}
\end{aligned}
$$

where $r \rightarrow 0$ is assumed. Free entry and zero discounting imply that the steady-state flow of profits are equal to zero for both types of firms, i.e., $\pi_{k}=e\left(y_{e}-w_{e}\right)-\kappa v_{E}=p\left(y_{p}-w_{p}\right)-\kappa v_{P}=0$. 


\subsection{Equilibrium}

All the ingredients of the model are now in place. The key relationships are the two job creation equations and the two first-order conditions for optimal search along with the three equations for present value differences, i.e., (11), (12) and (13). We reproduce the equations for job creation and optimal search:

$$
\begin{aligned}
\frac{\left(y-w_{e}\right) h_{e}}{\phi} & =\frac{\kappa}{q\left(\theta_{E}\right)} \\
\frac{\left(y-w_{p}\right) h_{p}}{\phi+s_{p} \alpha\left(\theta_{E}\right)} & =\frac{\kappa}{q\left(\theta_{P}\right)} \\
\frac{\delta}{T-h_{p}-s_{p}} & =\alpha\left(\theta_{E}\right)(E-P) \\
\frac{\delta}{T-s_{u}} & =\alpha\left(\theta_{P}\right)(P-U)+\alpha\left(\theta_{E}\right)(E-U)
\end{aligned}
$$

The model has a simple recursive structure. $\theta_{E}$ is determined from (22). Hence $s_{p}$ is obtained from (24) using (13). Using these results, $\theta_{P}$ is obtained from (23) and finally $s_{u}$ from (25) using (11) and (12). The unemployment and underemployment rates, $u$ and $p$, are obtained from (2) and (3), noting that employment follows from $e=1-p-u$. One can use $S_{E} \equiv s_{u} u+s_{p} p$ and $S_{P}=s_{u} u$ to determine $S_{k}$ and by invoking $\theta_{k}=v_{k} / S_{k}$ we obtain the number of vacancies of either type.

Unemployment benefits are financed by a proportional tax at the rate $t$ on all types of labor income, including benefits. As already noted, such a tax does not affect the present value differences as given by (11), (12) and (13). It follows that the tax is neutral in the sense that it does not affect employment and unemployment. The tax rate can thus be computed residually once $e, p$ and $u$ are determined. The government's budget restriction is given by

$$
t\left[(1-u-p) W_{e}+u B+p\left(W_{p}+b\right)\right]=u B+p b
$$

which can be written as:

$$
\tau \equiv \frac{t}{1-t}=\frac{u B+p b}{(1-u-p) W_{e}+p W_{p}}
$$


A proportional tax on income including benefits at the rate $t$ is equivalent to a proportional wage tax on firms at the rate $t /(1-t)$.

\subsection{Comparative Statics}

We are mainly interested in the impact of benefits, $b$ and $B$. It is helpful to make use of envelope properties that follow from the fact that workers optimally choose search efforts. Hence $\partial U / \partial s_{u}=\partial P / \partial s_{p}=0$. From (8) follows that $\partial E / \partial s_{u}=0$ when evaluated at the optimal $s_{u}$. Moreover, $\partial P / \partial s_{u}=0$ follows from (9). When examining the impacts of $b$ and $B$, it is thus sufficient to look at the impacts via $v_{j}$. Table 1 summarizes some comparative statics results where signs in parentheses are numerical results based on a calibrated version of the model (see Appendix).

Table 1. Comparative statics

\begin{tabular}{|l|l|l|l|l|l|l|l|}
\hline \hline & $\theta_{E}$ & $\theta_{P}$ & $s_{u}$ & $s_{p}$ & $e$ & $p$ & $u$ \\
\hline$B$ & 0 & 0 & - & 0 & - & - & + \\
\hline$b$ & 0 & + & $(+)$ & - & $(-)$ & $(+)$ & $(-)$ \\
\hline \hline
\end{tabular}

When wages are fixed, an increase in $B$ has no impact on $\theta_{E}$ and hence no impact on $s_{p}$ and therefore, via (23), no impact on $\theta_{p}$. From (22) also follows that $\partial \theta_{E} / \partial b=0$. An increase in $b$ reduces the utility difference $(E-P)$ and thus the returns to search while part-time unemployed; thus $\partial s_{p} / \partial b<0$. Using also (23) we get $\partial \theta_{p} / \partial b>0$. To understand this result, note that a decline in $s_{p}$ increases the value to firms of part-time jobs since workers stay longer as part-timers; hence the incentive to open more part-time vacancies increases.

The impact on $s_{u}$ is slightly more involved. Consider the first-order condition for $s_{u}$ as given by $(25)$ and note that $B$ enters via $(P-U)$ and $(E-$ $U)$. Clearly, a higher $B$ reduces both utility differences and thus $\partial s_{u} / \partial B<0$. The impact of $b$ works via $\alpha\left(\theta_{P}\right),(P-U)$ and $(E-U)$, where $\theta_{P}$ increases and $E-U$ decreases with a rise in $b$. Note that $(P-U)$ increases with a rise in $b$, a fact that reflects that part-time benefits is akin to an in-work subsidy. It is difficult to sign $\partial s_{u} / \partial b$ but the ambiguity is of some interest since it 
suggests that high benefits to part-timers may have negligible consequences for unemployment. Indeed, for all calibrations of the model we find that $\partial s_{u} / \partial b>0$, i.e., higher part-time benefits increase search efforts among the unemployed.

An increase in $B$ increases $u$ via reduced search efforts among the unemployed. This decline in $s_{u}$ implies a concomitant fall in $p$ via lower inflow into part-time work. The net effect on employment is negative: the rise in $u$ is bigger than the decline in $p$.

The ambiguity of $\partial s_{u} / \partial b$ makes it impossible to determine how an increase in $b$ affect $u$ and $p$. However, if $\partial s_{u} / \partial b>0$, it follows that $\partial u / \partial b<0$. Indeed, this is what the calibrated model implies. A rise in part-time benefits reduces unemployment as it encourages search effort among the unemployed. However, there is also a concomitant decline in the search effort among parttimers which will reduce the pace at which they locate full-time jobs. Higher part-time benefits therefore tend to increase part-time unemployment.

This completes the positive analysis and we turn to normative issues.

\section{Optimal Unemployment Insurance}

\subsection{Optimal Policy with Indefinite Benefit Payments}

We first consider a UI system with indefinite benefit payments. Benefits are financed by a proportional tax on wage income and benefits. We focus on steady states and ignore discounting, i.e., we let $r \rightarrow 0$. The relevant utilitarian welfare objective will then be the worker's expected utility which is a function of net income (consumption) in the three states:

$$
\Lambda=\ln (1-t)+u v_{u}(B)+p v_{p}\left(W_{p}+b\right)+(1-u-p) v_{e}\left(W_{e}\right)
$$

where wage incomes are given as $W_{e}=w_{e} h_{e}$ for full-timers and $W_{p}=w_{p} h_{p}$ for part-timers. Benefits can also be expressed in terms of replacement rates, $\rho_{j}$, i.e., $B=\rho_{e} W_{e}$ and $b=\rho_{p}\left(W_{e}-W_{p}\right)$. Substitute the budget restriction 
as given by (26) into the welfare objective and obtain:

$$
\Lambda=-\ln [1+\tau(.)]+u v_{u}(B)+p v_{p}\left(W_{p}+b\right)+(1-u-p) v_{e}\left(W_{e}\right)
$$

where we have used $\tau \equiv t /(1-t)$ and $\tau($.$) is given by (27). Absent moral$ hazard, i.e., with exogenous search effort, it is straightforward to confirm that optimal insurance is full insurance, i.e., equal incomes in the three states: $W_{e}=B=W_{p}+b$. However, search effort responds to benefits and full insurance will not be optimal. We have to recognize that changes in $B$ and $b$ affect search and thereby $e, p$ and $u$.

The welfare effect of a policy is measured relative to the baseline. It is expressed as the equivalent of a consumption tax that equalizes welfare across policy regimes. Let $\Lambda^{U}$ represent welfare associated with the benchmark and $\Lambda^{A}$ welfare associated with an alternative policy. The measure of the welfare gain of policy $A$ relative to policy $U$ is given by the value of the tax rate $x$ that solves $\Lambda^{A}[(1-x) w ; \cdot]=\Lambda^{U}$. With logarithmic utility functions we have $\Delta \Lambda \equiv \Lambda^{A}-\Lambda^{U}=-\ln (1-x) \approx x$.

Our calibrated model replicates some key features of the Swedish labor market. For details about the calibration, see Appendix. We consider a baseline case with unemployment at 7 percent and part-time unemployment at 4 percent. The statutory replacement ratio can be as high as 80 percent in Sweden (and possibly higher for some groups that are covered by UI provided by collective agreements). However, coverage of UI is relatively low: only a third of the unemployed are covered by UI. We set the replacement rate to 0.3 for the unemployed as well as for part-timers to capture incomplete coverage as well as finite benefit duration. Table 2 shows the baseline outcome along with the outcomes associated with optimal uniform replacement ratios, $\rho_{u}=\rho_{p}$, as well as optimally differentiated benefits.

The optimal uniform system involves a replacement rate slightly higher than the benchmark 30 percent. The rise in the replacement rate leads to a decline in unemployed search as well as in part-time search. Unemployment as well as part-time unemployment increases as the outflow rates decline. The welfare gain relative to the baseline amounts to 0.56 percent of consumption. The optimally differentiated system, displayed in the third column, yields 
further welfare gains. The replacement rate for the unemployed increases whereas it declines for part-timers compared to the optimal uniform system.

Table 2. Optimal UI, indefinite benefit payments.

\begin{tabular}{|c|c|c|c|}
\hline & $\begin{array}{c}\text { Baseline } \\
\text { case }\end{array}$ & $\begin{array}{c}\text { Optimal } \\
\text { uniform }\end{array}$ & $\begin{array}{c}\text { Optimally } \\
\text { differentiated }\end{array}$ \\
\hline$\rho_{u}$ & 0.300 & 0.370 & 0.390 \\
$\rho_{p}$ & 0.300 & 0.370 & 0.330 \\
$s_{u}$ & 1.019 & 0.897 & 0.852 \\
$s_{p}$ & 0.400 & 0.296 & 0.361 \\
$u$ & 0.070 & 0.074 & 0.081 \\
$p$ & 0.040 & 0.061 & 0.046 \\
$e$ & 0.890 & 0.865 & 0.873 \\
$t$ & 0.028 & 0.040 & 0.041 \\
\hline Welfare & & \multicolumn{2}{|l}{} \\
$\Delta \Lambda(\%)$ & & 0.56 & 0.72 \\
\hline \hline
\end{tabular}

How robust are these results? We focus on earnings among part-timers, $W_{p}=w_{p} h_{p}$, relative to earnings among employed workers, $W_{e}=w_{p} h_{p}$; the more income protection through part-time work, the less need for part-time benefits. Figure 1 shows how optimally differentiated replacement rates vary by the ratio $W_{p} / W_{e}$, where changes in the earnings ratio is produced by varying $h_{p} / h_{e}$. Our baseline calibration involves $W_{p} / W_{e}=0.45$, a ratio obtained from $h_{p} / h_{e}=0.5$ (consistent with Swedish data) and $w_{p} / w_{e}=0.9$ (as empirical work has estimated a wage penalty for part-timers). Four levels of the earnings ratio are considered: $0.2,0.4,0.6$ and 0.8 . The optimal replacement rate for the unemployed is relatively insensitive to the earnings ratio whereas the replacement rate for part-timers declines sharply as the relative earnings ratio increases.

\subsection{Optimal Policy with Time Limits}

So far we have assumed that benefits last forever. Now let's consider time limits for $B$ and $b$. This is modelled along the lines of Fredriksson and Holm- 
lund (2001). Benefits expire randomly at the rate $\lambda$ for full-time unemployed and the rate $\mu$ for part-timers. When UI benefits expire, workers have access to unemployment assistance and are referred to as non-insured. The value function for $U$ is modified so as to distinguish between those insured $(I)$ and those non-insured $(N)$. Insured full-timers get $B^{I}=\rho_{u}^{I} W_{e}$ whereas those not insured get $B^{N}=\rho_{u}^{N} W_{e}$. Part-timers receive $b^{I}=\rho_{p}^{I}\left(W_{e}-W_{p}\right)$ if insured and $b^{N}=\rho_{p}^{N}\left(W_{e}-W_{p}\right)$ if not insured. We need to distinguish between search effort among those insured and those not insured. Moreover, we have to recognize that there are two groups of full-time unemployed, insured and not insured, as well as two groups of part-timers:

$$
\begin{aligned}
& u=u^{I}+u^{N} \\
& p=p^{I}+p^{N}
\end{aligned}
$$

The tightness concepts are as before but we note that the total number of searchers in efficiency units is

$$
\begin{aligned}
& S_{E}=s_{u}^{I} u^{I}+s_{u}^{N} u^{N}+s_{p}^{I} p^{I}+s_{p}^{N} p^{N} \\
& S_{P}=s_{u}^{I} u^{I}+s_{u}^{N} u^{N}
\end{aligned}
$$

The modified value functions are given as:

$$
\begin{aligned}
r E= & v_{e}+\phi\left(U^{I}-E\right) \\
r U^{I}= & v_{u}^{I}+s_{u}^{I}\left[\alpha\left(\theta_{P}\right)\left(P^{I}-U^{I}\right)+\alpha\left(\theta_{E}\right)\left(E-U^{I}\right)\right] \\
& +\lambda\left(U^{N}-U^{I}\right) \\
r U^{N}= & v_{u}^{N}+s_{u}^{N}\left[\alpha\left(\theta_{P}\right)\left(P^{I}-U^{N}\right)+\alpha\left(\theta_{E}\right)\left(E-U^{N}\right)\right] \\
r P^{I}= & v_{p}^{I}+\phi\left(U^{I}-P^{I}\right)+s_{p}^{I} \alpha\left(\theta_{E}\right)\left(E-P^{I}\right)+\mu\left(P^{N}-P^{I}\right) \\
r P^{N}= & v_{p}^{N}+\phi\left(U^{I}-P^{N}\right)+s_{p}^{N} \alpha\left(\theta_{E}\right)\left(E-P^{N}\right)
\end{aligned}
$$

Employed workers as well as part-timers are immediately eligible for UI when laid off. The flow value of being insured unemployed, $r U^{I}$, includes a term that captures the risk of benefit expiration and the associated change in the value of unemployment, $\lambda\left(U^{N}-U^{I}\right)$. When the non-insured unemployed worker finds a part-time job, she becomes immediately eligible for part-time benefits; the change in the state values is thus given by 
$P^{I}-U^{N}$. The flow value of being an insured part-timer, $r P^{I}$, involves the term $\mu\left(P^{N}-P^{I}\right)$ that captures the risk of benefit termination and the related change in the value of being part-time unemployed.

The relevant utility functions are:

$$
\begin{aligned}
v_{u}^{I} & =\ln B^{I}+\delta \ln \left(T-s_{u}^{I}\right) \\
v_{u}^{N} & =\ln B^{N}+\delta \ln \left(T-s_{u}^{N}\right) \\
v_{p}^{I} & =\ln \left(w_{p} h_{p}+b^{I}\right)+\delta \ln \left(T-h_{p}-s_{p}^{I}\right) \\
v_{p}^{N} & =\ln \left(w_{p} h_{p}+b^{N}\right)+\delta \ln \left(T-h_{p}-s_{p}^{N}\right) \\
v_{E} & =\ln \left(w_{e} h_{e}\right)+\delta \ln \left(T-h_{e}\right)
\end{aligned}
$$

Optimal search effort is obtained as:

$$
\begin{aligned}
s_{p}^{I} & : \quad \frac{\delta}{T-h_{p}-s_{p}^{I}}=\alpha\left(\theta_{E}\right)\left(E-P^{I}\right) \\
s_{p}^{N} & : \quad \frac{\delta}{T-h_{p}-s_{p}^{N}}=\alpha\left(\theta_{E}\right)\left(E-P^{N}\right) \\
s_{u}^{I} & : \quad \frac{\delta}{T-s_{u}^{I}}=\alpha\left(\theta_{P}\right)\left(P^{I}-U^{I}\right)+\alpha\left(\theta_{E}\right)\left(E-U^{I}\right) \\
s_{u}^{N} & : \quad \frac{\delta}{T^{\prime}-s_{u}^{N}}=\alpha\left(\theta_{P}\right)\left(P^{I}-U^{N}\right)+\alpha\left(\theta_{E}\right)\left(E-U^{N}\right)
\end{aligned}
$$

The usual optimality conditions apply: the marginal cost of increasing search effort should be equated to the expected marginal gain of doing so. A comparison of (39) and (41) reveals that the marginal gain of increasing search effort is higher for an unemployed insured worker than for an insured part-timer as long as $P^{I}>U^{I}$; indeed, $P^{I}>U^{I}$ must hold in order to induce the unemployed worker to accept part-time jobs. It follows that the insured unemployed worker allocates more effort to job search than the insured parttimer, i.e., $s_{u}^{I}>s_{p}^{I}$. An analogous argument implies that the non-insured unemployed worker allocates more effort to job search than the non-insured part-timer, i.e., $s_{u}^{N}>s_{p}^{N}$. We also note that $s_{p}^{I}<s_{p}^{N}$ as well as $s_{u}^{I}<s_{u}^{N}$ holds under the assumptions that the optimal policy implies $U^{I}>U^{N}$ and $P^{I}>P^{N}$ : benefit cuts boost search effort by increasing the marginal gain from additional search. 
There will be six policy parameters in the most general case, viz. four replacement rates, $\rho_{u}^{I}, \rho_{u}^{N}, \rho_{p}^{I}, \rho_{p}^{N}$, as well as two parameters determining the potential duration of benefit receipt, $\lambda$ and $\mu$. We proceed by focusing on two special cases. The first case involves indefinite unemployment benefits whereas part-time benefits are subject to time limits. In this case, there are four policy parameters of interest, viz. $\rho_{u}, \rho_{p}^{I}, \rho_{p}^{N}$ and $\mu$. The second case we consider entails indefinite part-time benefits but unemployment benefits with time limits. The four policy parameters of interest are thus $\rho_{p}, \rho_{u}^{I}, \rho_{u}^{N}$ and $\lambda$.

\subsubsection{Special Case I: Time Limits for Part-time Benefits}

The flow equilibrium condition for unemployment remains intact for the first special case. For part-timers flow equilibrium implies:

$$
\begin{aligned}
p^{I} & =\frac{s_{u} \alpha\left(\theta_{P}\right) u}{\phi+s_{p}^{I} \alpha\left(\theta_{E}\right)+\mu} \\
p^{N} & =\frac{\mu p^{I}}{\phi+s_{p}^{N} \alpha\left(\theta_{E}\right)}
\end{aligned}
$$

Time limits pertaining to part-time benefits affect the value to firms of having part-timers employed. When an insured part-timer loses benefits, her search effort is affected and thereby the probability of landing a full-time job and thus the leaving the firm. The value functions take the form:

$$
\begin{aligned}
r J_{P}^{I}= & \left(y_{p}-w_{p}\right) h_{p}+\phi\left(V_{P}-J_{P}^{I}\right)+s_{p}^{I} \alpha\left(\theta_{E}\right)\left(V_{P}-J_{P}^{I}\right) \\
& +\mu\left(J_{P}^{N}-J_{P}^{I}\right) \\
r J_{P}^{N}= & \left(y_{p}-w_{p}\right) h_{p}+\phi\left(V_{P}-J_{P}^{N}\right)+s_{p}^{N} \alpha\left(\theta_{E}\right)\left(V_{P}-J_{P}^{N}\right) \\
r V_{P}= & -\kappa+q\left(\theta_{P}\right)\left(J_{P}^{I}-V_{P}\right)
\end{aligned}
$$

where the term $\mu\left(J_{P}^{N}-J_{P}^{I}\right)$ in (45) captures the fact that the insured parttimer loses benefits at the rate $\mu$ which brings about a change in the value to the firm of having a part-timer employed. The value functions imply

$$
J_{P}: \frac{\left(y_{p}-w_{p}\right) h_{p}\left[1+\frac{\mu}{\phi+\alpha\left(\theta_{E}\right) s_{p}^{N}}\right]}{\mu+\phi+\alpha\left(\theta_{E}\right) s_{p}^{I}}=\frac{\kappa}{q\left(\theta_{P}\right)}
$$


when $r \rightarrow 0$ and $V=0$.

The equilibrium of this economy is obtained from three first-order conditions for optimal search $\left(s_{u}, s_{p}^{I}\right.$ and $\left.s_{p}^{N}\right)$ along with the free entry conditions for firms, and the flow equilibrium conditions. To determine optimal search, we also need to make use of the present value differences $P^{I}-U, E-U$, $E-P^{I}$ and $E-P^{N}$ which are obtained from the value functions given by $(34)-(38)$.

The welfare function is slightly modified and take the form:

$$
\begin{aligned}
\Lambda= & \ln (1-t)+u\left[\ln B+\delta \ln \left(T-s_{u}\right)\right]+(1-u-p)\left[\ln \left(W_{e}\right)+\delta\left(T-h_{e}\right)\right] \\
& +p^{I}\left[\ln \left(W_{p}+b^{I}\right)+\delta \ln \left(T-h_{p}-s_{p}^{I}\right)\right] \\
& +p^{N}\left[\ln \left(W_{p}+b^{N}\right)+\delta \ln \left(T-h_{p}-s_{p}^{N}\right)\right]
\end{aligned}
$$

Benefits are financed by a proportional tax on all income, including benefits. The budget constraint for the government then implies:

$$
\frac{t}{1-t}=\frac{u B+p^{I} b^{I}+p^{N} b^{N}}{(1-u-p) W_{e}+p W_{p}}
$$

Table 3 presents numerical results. The previous results for indefinite and uniform benefit payments are reproduced in the first two columns. The third column shows the effects of introducing time limits pertaining to part-time benefits while maintaining indefinite benefits payments for the unemployed. The optimal time profile involves steeply declining part-time compensation; the replacement rate is 0.76 in the first tier and 0.26 in the second. The optimal value of $\mu$ implies that the expected duration of part-time insurance benefits should be 38 weeks. The replacement rate for (indefinite) unemployment insurance increases to 0.41 which brings about a decline in search effort while unemployed and a rise in unemployment. The welfare gain relative to the benchmark amounts to 0.81 percent of consumption. 
Table 3. Optimal UI with time limits (TL).

\begin{tabular}{|c|c|c|c|c|c|}
\hline & $\begin{array}{c}\text { Baseline } \\
\text { case }\end{array}$ & $\begin{array}{c}\text { Optimal } \\
\text { uniform }\end{array}$ & $\begin{array}{c}\text { TL for } \\
\text { part-timers }\end{array}$ & $\begin{array}{c}\text { TL for } \\
\text { unemployed }\end{array}$ & $\begin{array}{c}\text { TL for } \\
\text { both groups }\end{array}$ \\
\hline$\rho_{u}^{I}$ & 0.300 & 0.370 & 0.410 & 0.580 & 0.670 \\
$\rho_{u}^{N}$ & & & & 0.350 & 0.370 \\
$\rho_{p}^{I}$ & 0.300 & 0.370 & 0.750 & 0.360 & 0.910 \\
$\rho_{p}^{N}$ & & & 0.260 & & 0.260 \\
$\mu$ & 0 & 0 & 0.026 & 0 & 0.025 \\
$\lambda$ & 0 & 0 & 0 & 0.048 & 0.048 \\
$s_{u}^{I}$ & 1.019 & 0.897 & 0.804 & 0.797 & 0.708 \\
$s_{u}^{N}$ & & & & 0.945 & 0.910 \\
$s_{p}^{I}$ & 0.400 & 0.296 & 0.293 & 0.314 & 0.226 \\
$s_{p}^{N}$ & & & 0.443 & & 0.443 \\
$u^{I}$ & 0.070 & 0.074 & 0.087 & 0.026 & 0.027 \\
$u^{N}$ & & & & 0.050 & 0.054 \\
$p^{I}$ & 0.040 & 0.061 & 0.011 & 0.056 & 0.013 \\
$p^{N}$ & & & 0.028 & & 0.030 \\
$e$ & 0.890 & 0.865 & 0.874 & 0.868 & 0.876 \\
$t$ & 0.028 & 0.040 & 0.046 & 0.044 & 0.050 \\
\hline Welfare & & & & & \\
$\Delta \Lambda(\%)$ & & 0.56 & 0.81 & 0.97 & 1.16 \\
\hline \hline
\end{tabular}

\subsubsection{Special Case II: Time Limits for Unemployment Benefits}

We now consider a policy where unemployment benefits are subject to time limits whereas part-time benefits are paid indefinitely. The relevant policy parameters are thus $\rho_{p}, \rho_{u}^{I}, \rho_{u}^{N}$ and $\lambda$. The flow equilibrium equations for the two unemployment states and part-time unemployment are as follows:

$$
\begin{array}{rll}
u^{I}: & \phi\left(1-u^{I}-u^{N}\right)=\left(\lambda+s_{u}^{I}\left[\alpha\left(\theta_{P}\right)+\alpha\left(\theta_{E}\right)\right]\right) u^{I} \\
u^{N}: & \lambda u^{I}=s_{u}^{N}\left[\alpha\left(\theta_{P}\right)+\alpha\left(\theta_{E}\right)\right] u^{N} \\
p: & s_{u}^{I} \alpha\left(\theta_{P}\right) u^{I}+s_{u}^{N} \alpha\left(\theta_{P}\right) u^{N}=\left[\phi+s_{p} \alpha\left(\theta_{E}\right)\right] p
\end{array}
$$


The job creation conditions are given by (22) and (23), exactly as in a regime without any time limits.

The welfare function takes the form:

$$
\begin{aligned}
\Lambda= & \ln (1-t)+u^{I}\left[\ln B^{I}+\delta \ln \left(T-s_{u}^{I}\right)\right]+u^{N}\left[\ln B^{N}+\delta \ln \left(T-s_{u}^{N}\right)\right] \\
& +p\left[\ln \left(W_{p}+b\right)+\delta \ln \left(T-h_{p}-s_{p}\right)\right] \\
& +(1-u-p)\left[\ln \left(W_{e}\right)+\delta\left(T-h_{e}\right)\right]
\end{aligned}
$$

and the government's budget constraint implies:

$$
\frac{t}{1-t}=\frac{u^{I} B^{I}+u^{N} B^{N}+p b}{(1-u-p) W_{e}+p W_{p}}
$$

The fourth column in Table 3 presents the effects of introducing time limits for unemployment benefits. This policy beats the optimal uniform system by 0.4 percent of consumption and a system with time-limits for part-timers (the third column) by the equivalent of almost 0.2 percent of consumption. The first UI tier entails a replacement rate of 0.58 whereas the second is 0.35 . The optimal value of $\lambda$ implies that the expected duration of potential UI receipt should be set to 21 weeks. The fraction of non-insured among the unemployed will be twice as large as the fraction of insured.

\subsubsection{General Case with Six Policy Instruments}

We finally consider the most general case with optimally chosen time limits for both part-time benefits and unemployment benefits. The results are displayed in the fifth column of Table 3. The two UI tiers involve replacement rates of 0.67 and 0.37 , whereas the replacement rates for the part-time tiers are 0.91 and 0.26 . The optimal duration of potential benefit receipt is 40 weeks for part-time benefits and 21 weeks for unemployment benefits. Benefits for part-timers are thus initially more generous than unemployment benefits but the time profile of benefit receipt declines more sharply for parttimers. The welfare gain relative to an optimal uniform system amounts to 0.6 percent of consumption. 


\section{Discussion}

There are a number of conceivable extensions of the model. For example, one might consider introducing endogenous wage determination through Nash bargaining (although it is not obvious that individual Nash bargaining over wages is the best model for wage determination in Sweden where collective bargaining plays a crucial role). In any case, we conjecture that search effort is the most important margin of adjustment when analyzing UI reforms.

We have treated preferences as uniform across individuals, a simplification that is bound to be patently unrealistic. Introducing heterogeneity in preferences, such as heterogeneity in the preference for leisure, raises new issues. When preferences are private information, it will be difficult for the policy maker to distinguish between voluntary and involuntary part-time work. In particular, the policy must be structured so that those who prefers part-time work are excluded from benefits intended for workers who are involuntary unemployed.

An interesting policy issue concerns the financing of UI. Is there a case for employer co-financing of part-time benefits? Probably there is, but to deal with this issue one would like to have a model with endogenous wage determination.

\section{APPENDIX}

\section{The Numerical Model}

The matching function is Cobb Douglas, $M=a u^{\eta} v^{1-\eta}$, where $\eta=0.5$ is assumed; this is broadly consistent with most empirical studies. Productivity is normalized to unity for both part-time and full-time employees: $y_{e}=y_{p}=$ 1. The time period is taken to be a week. The rate of interest (equal to the rate of time preference) is set to zero.

Measures of flows from employment to unemployment can be derived from the Swedish labor force surveys. We have obtained data on the inflow from employment to unemployment by using data on the number of short-term unemployed (one week of elapsed unemployment duration among entrants 
into unemployment from employment). The annual separation rate is around 10 percent and we thus set the weekly rate to $0.10 / 52=0.0019$.

As noted above, coverage of UI is relatively $\operatorname{low}^{2}$ and we account for this by choosing a benchmark replacement rate of 30 percent, i.e., $\rho_{u}=\rho_{p}=0.3$. The parameters $T$ and $\delta$ are guided by empirical results regarding the partialequilibrium responsiveness of job finding to changes in benefits. Estimates of the job finding elasticity with respect to benefits center around 0.5 ; this would imply $d \ln s / d \ln B \approx-0.5$ since the job finding rate is given by $f=s \alpha(\theta)$ and tightness is taken as given in the partial equilibrium context. We end up with $T=1.5912$ and $\delta=0.65$ using a conventional model with only two states, i.e., employment and unemployment.

Regarding work hours we assume that the full-time worker works as much has she prefers. This implies

$$
h_{e}=\frac{T}{1+\delta}
$$

since this is the worker's preferred working time given the preferences we have assumed. Working time among part-timers is given by $h_{p}=0.5 h_{e}$, which is in line with Swedish data: part-timers in the labor force surveys report that they wish to work twice as much as they actually do.

Regarding wages, empirical work has documented wage penalties for parttimers. A recent Swedish study by Wahlberg (2008) suggests a wage penalty of 20 percent, perhaps implausibly large. We set $w_{p} / w_{e}=0.9$. When setting $w_{e}$ we are guided by the outcome from a calibrated standard two-state model with symmetric Nash bargaining over wages. This leads to $w_{e}=0.95$

The matching parameter $a$, and the vacancy cost $\kappa$ are chosen so as to obtain 7 percent unemployment and a part-time rate somewhat below the unemployment rate We set $a=0.06$ and $\kappa=4.7$ and end up with $p=0.04$. We have no data on our measures of tightness, $\theta_{k}$ since we don't observe search effort and vacancies for part-timers

The parameterized model produces outcomes as given by the first column in Table 2 in the main text.

\footnotetext{
${ }^{2}$ According to the labor force surveys, around one third of the unemployed received unemployment benefits over the period 2005-2009.
} 


\section{References}

Fagan, C and J O'Reilly, eds. (1998), Part-Time Prospects: An International Comparison, Routledge.

Fredriksson. P and B Holmlund (2001), Optimal Unemployment Insurance in Search Equilibrium, Journal of Labor Economics 19, 370-399.

Hartman, L, ed. (2008), Välfärd på deltid, SNS Förlag.

Pissarides, C (2000), Equilibrium Unemployment Theory, MIT Press.

Wahlberg, R (2008), Part-Time Penalty in Sweden: Evidence from Quantile Regression, Working Paper in Economics 315, University of Gothenburg 